УДК 54.02:737

https://doi.org/10.24852/2587-6112.2020.5.214.226

\title{
ХИМИЧЕСКИЙ СОСТАВ СЕРЕБРЯНЫХ МОНЕТ ВТОРОЙ ПОЛОВИНЫ ХIV- ПЕРВОЙ ТРЕТИ ХV ВВ., ИМЕВШИХ ХОЖДЕНИЕ В БОЛГАРСКОМ УЛУСЕ
}

\author{
(C) 2020 г. П.В. Федан, Д.Г. Мухаметшин, Р.Х. Храмченкова, А.Г. Ситдиков
}

Целью представленной работы является определение динамики изменения серебряных монет Золотой Орды и Болгарского улуса второй половины XIV - первой трети XV вв. в контексте исторических событий и катаклизмов путем анализа нумизматического материала и определения химического состава. В изученную выборку из 23 фрагментов серебряных денег вошли монеты Болгарского чекана, подражания джучидским дангам, обрезанные и надчеканенные монеты, а также в качестве элемента сравнения - монета Крымского ханства. Концентрация элементов в металле образцов определялась двумя независимыми аналитическими методами - неразрушающим рентгенофлуоресцентным (XRF) и эмиссионным спектральным (ESA). XRF-анализ проводился как на поверхности, так и на изломе монет. Сравнение результатов по содержанию основных компонентов монетных сплавов выявило различие в концентрации серебра и меди, определенных на поверхности и изломе. Результаты ESA и XRF (на изломе) показали хорошую сопоставимость и позволили выявить тенденции в изменении химического состава в зависимости от времени и правителя.

Ключевые слова: археология, серебряные монеты, XIV - XV века, Болгарский Улус, химический состав.

\section{CHEMICAL COMPOSITION OF SILVER COINS OF THE SECOND HALF OF $14^{\mathrm{TH}}$ - FIRST THIRD OF $15^{\mathrm{TH}}$ CENTURIES IN CIRCULATION IN THE BOLGAR ULUS}

\section{P.V. Fedan, D.G. Mukhametshin, R.Kh. Khramchenkova, A.G. Sitdikov}

The aim of this work is to determine the dynamics of changes of silver coins of the Golden Horde and the Bolgar ulus in the second half of $14^{\text {th }}$ - the first third of $15^{\text {th }}$ century in the context of historical events and disasters by means of an analysis of the numismatic material and determination of chemical composition. The studied group consists of 23 fragments of various silver coins: coins minted in Bulgaria, imitations of Juchid dangas, cut and countermarked coins, and a coin of the Crimean khanate as material for comparison. The concentration of elements in the metal samples was determined using two independent analytical methods non-destructive x-ray fluorescence (XRF) and emission spectral (ESA) analysis. XRF analysis was performed both on the surface and on the fractures of the coins. A comparison of the results in the content of the main components of metal alloys revealed a difference in the concentration of silver and copper, identified on the surface and on the fracture. The ESA and XRF results (obtained on the fracture) showed good comparability and allowed to identify trends in chemical composition changes depending on the period and ruler.

Keywords: archaeology, silver coins, $14^{\text {th }}-15^{\text {th }}$ centuries, Bolgar Ulus, chemical composition.

\section{Введение}

Во второй половине XIV века в Золотой Орде в результате междоусобных войн усиливаются центробежные силы, что приводит к распаду единого монетного пространства. Ослабление экономики привело к удорожанию серебра и изъятию его у населения. Существенное замедление чеканки полновесных серебряных монет вызвало на Среднем Поволжье нехватку средств обращения и положило начало надчеканки старых медных и серебряных монет.

Первое изменение веса серебряных монет было отмечено при Абдаллахе. Так, вес части монет, изготовленных в период с
(762-772 г.Х.=1361-1371 гг.), снижается с 1,56 г. до 1,365 г. (Мухамадиев, 1983). Последующая реформа хана Токтамыша в 1381 г. констатировала факт разных весовых норм для Крыма, Азака - 1,10 г., и для остальных областей Золотой Орды - 1,56 г. В это время Болгар не чеканил монеты с указанием монетного двора Болгар, а обрезал старые монеты под различные веса. Болгарский монетный двор чуть позднее контрамаркировал обрезанные монеты специальной тамгой.

Поражение хана Токтамыша от Тамерлана привело к окончательному отделению Булгарских земель от центральной власти. В начале XV в. хан Шадибек (1400-1407 гг.) провел 
денежную реформу, в результате которой вес монеты уменьшился до 0,71-0,77 г., в дальнейшем при хане Дервише (1417 г.) - до 0,620,65 г, а при хане Гияс ад-Дине (1422-1445 г.) вес монеты составлял уже 0,55-0,57 г. (Мухамадиев, 1983).

На территории Среднего Поволжья серебряные монеты Шадибека и последующих ханов отложились, в основном, в кладах: Сингелеевский (1956), Измерский (1961), Караулная Гора (1957), Войкино (1933), Кожаевский (2008), Большие Атряссы, Билярский (2012), Торецкое поселение (2005) и других. В раскопках Болгара монеты XV в. представлены единичными находками. По материалам Поволжской археологической экспедиции монет с надчеканками - 9 единиц, именная монета Шадибека - 1 единица. Монетвторой половины 20-x - 30-х гг. XV века на Болгарском городище обнаружено не было.

Крайне редкими являются находки отдельных монет Пулада (810-813 г.х.=1407-1410), что говорит о слабом денежном обращении в начале XV в., сконцентрированном только в крупных городах. Они в значительном количестве чеканены в Болгаре (есть написание в форме Раджан) и в Болгар ал-Джадиде.

Многолетние исследования серебряного нумизматического материала второй половины XIV - начала XV вв. большей частью затрагивали типологизацию монет по историко-культурному происхождению. Изучение их химического состава долгое время было сопряжено с рядом трудностей. Основная сложность заключается в правильном отборе образца для изучения точными физико-химическими методами, поскольку монеты этого периода имеют небольшие размеры.

В последние годы в литературных источниках отмечается существенный рост числа работ по археометрическим исследованиям серебряных монет. В качестве аналитических средств изучения металлических денег исследователи применяют различные методы, начиная от классического эмиссионного спектрального анализа (ESA) (Беговатов и др., 2013; Лебедев и др., 2012), популярного неразрушающего метода рентгенофлуоресцентного анализа XRF (Pitarch и др., 2011, pp. 308-312; (Ioanid и др., 2011, pp. 220-226; Kantarelou и др., 2011, рр. 681-690), заканчивая более современными и тонкими методами, такими как двухимпульсная лазерная атомно-эмиссионная спектроскопия (Voropai и др., 2013, pp. 11-16), сканирующая электронная микро- скопия (Khramchenkova и др., 2018, pp. 1-23). (Sitdikov и др., 2017. с. 170-176.) и электронная томография (Шайхутдинова и др., 2016, с. 113-119).

В рамках данного исследования был проведен анализ 23-х серебряных монет второй половины - XIV первой трети XV вв., включающих Болгарский чекан, подражания джучидским дангу, надчеканы, обрезанные монеты, а также монета Крымского ханства в качестве элемента сравнения. Предметом исследования явился химический состав монет, который определялся двумя независимыми аналитическими методами - неразрушающим рентгенофлуоресцентным (XRF) и эмиссионным спектральным (ESA). XRF-анализ проводился как на поверхности, так и на изломе монеты.

\section{Материалы и методы}

В изучаемую выборку вошли 23 серебряные монеты из фондов Музея археологии Республики Татарстан, среди которых 11 монет второй половины XIV в.: 8 монет обрезанных, две обрезанных надчеканенных, а также 13 монет первой трети XV в. Описание, атрибуция и фотографии нумизматического материала приведены в табл. 1.

Нумизматический материал, представленный монетами нескольких эмитентов и монетных дворов, был изучен тремя независимыми аналитическими методами.

XRF определение проводилось на спектрометре MISTRAL фирмы Bruker со следующим режимом съемки: $\mathrm{HV} / \mathrm{kV}-50$, Current / $\mu \mathrm{A}-$ 800, Colli1 / mm - 1500, Colli2 / mm - 1500 . В качестве аналитического объекта были выбраны три различные точки на поверхности (рис. 1: а) и две точки на изломе монет (рис. 1: б), измерение содержаний элементов для каждой точки проводилось дважды. Окончательные концентрации получались в результате усреднения шести показаний для поверхности и четырех - для излома.

Методика анализа методом ESA описаны в (Khramchenkova и др., 2017 Pр. 87-93; Khramchenkova и др., 2017 pp.180-184.). В нашем случае для исследования от фрагментов монет были отобраны навески по 10 мг, которые затем были разделены на две. Усредненные результаты двух определений ESA были взяты в качестве итоговых значений концентраций элементов. В табл. 2 для каждой монеты приведены результаты анализа и эмиссионная спектроскопия ESA. Для каждой монеты приведены результаты анализа поверхности и излома методом 
$\mathrm{XRF}$, третьей строкой даны результаты исследования аналитической навески методом ESA.

\section{Результаты и обсуждение}

Методически выверенные исследования двумя независимыми методами дали объективную информацию о химическом составе нумизматического материала. Изучение неразрушающим методом поверхности и излома фрагментов выявили закономерную особенность распределения серебра в серебряных монетах. Практически для всех монет содержание благородного элемента на поверхности существенно выше его концентрации внутри. Диаграммы рисунка 2 показывают распределение монет согласно содержанию серебра на поверхности (рис. 2: а) и на изломе (рис. 2: б). Исключение составляет монета Гийас- ад-Дина с самым низким серебром в 13,5\%, которую практически можно считать медной с небольшой добавкой серебра. Минимальное различие в 1-3\% отмечается в высокопробных монетах, самая большая разница зафиксирована в монетах № 24 Мингли Гарай (Крымское ханство) и № 20 Гиайсад-Дин с содержанием серебра на поверхности/изломе $79,75 \% / 46,34 \%$ и $61,25 \% / 49,26 \%$ соответственно.

Сравнение результатов, полученных двумя методами, показала хорошую сопоставимость между данными ESA и XRF для излома. Некоторые различия можно объяснить тем, что эмиссионная спектроскопия определяет валовое содержание элемента во всей изучаемой навеске, в то время как ренгенофлуоресценция определяет поверхностный состав. В связи с большой разницей показателей концентраций для монеты №20 Гиайс-ад-Дин приведены оба результата ESA - 49,26\% и 31,77\%. Учитывая тот факт, что XRF данные для этой монеты также существенно различаются, такой разброс может говорить либо о плохо перемешанном сплаве, либо об аналитических навеcax ESA c различных участков исследованных нумизматических фрагментов.

По содержанию серебра монетный материал можно разделить на четыре группы: монеты с серебром больше 90\%, 80\% - 90\%, примерно 30\%-50\%, меньше 30\%.

Первая группа. Характерно, что самыми высокопробными образцами являются более ранние данги 747-767гг.х. - монеты №9 Джанибека (Сарай ал-Джадид), №4 Кульпы (Гулистан) и №7Азиз-Шейха (Гулистан). Эти монеты обрезаны, а №9 снадчеканом, серебро в них превышает 95\%. Более низкое содержание благородного металла до 90\% зафиксировано в подражаниях дангу Кильдибека и $778=877$ гг. х., а так же в монете Абдаллаха(Орда) 770 г.х.

Вторая группа. Во всех монетах Шадибека и Пулада серебро достаточно высокое - более $80 \%$. Однако, его значения не превышают 90\%. В эту же группу вошла монета Мухаммада с трехногой тамгой, Джанибека (Сарай ал-Джадид, 747 г.х.) и два подражания - джучидскому дангу (Сарай ал-Джадид?) и золотоордынскому дангу (Л.c. - Гулистан?, O.C. - Сарай ал-Джадид, 763 г.х.).

Третья группа. В этой группе два образца со средним значением концентрации серебра 40-44\% - монета №20 Гийас-ад-Дина и монета №24 Мингли-Гарай (Крымское ханство), а также монеты №18 Мухаммада (Болгар) и №21 с солярным знаком. У них содержание серебра около $30 \%$.

Четвертая группа. Две монеты №№19, 23 Гийас-ад-Дина являются самыми низкопробными, в них серебро не превышает значений $22 \%$.

Интересные особенности монетных сплавов демонстрируют диаграммы соотношения меди и серебра с золотом и свинцом, приведенные на рис. 3.

Как можно увидеть из диаграмм, для многих сплавов наблюдается обратная корреляция меди и прямая серебра с золотом и свинцом. Это может свидетельствовать об определенных источниках серебряной руды. В то же время, таблица 1 демонстрирует высокопробные монеты, в срединной части которых по данным XRF выявлены повышенные содержания меди с коррелирующим свинцом (монеты №№1, 2, 10, 12, 17, что может указывать на монеты типа «сэндвич» (Храмченкова и др. , 2015, с. 176-188.). Однако для исследуемой выборки характерно невысокое содержание свинца по сравнению с монетами X-XI вв., поэтому более точную информацию о структуре и технологии изготовления монет можно будет дать только после изучения их более тонким методом электронной микроскопии.

Рисунок 4 демонстрирует статистическую диаграмму распределения всех компонентов сплава по данным ESA.

Это распределение формирует четыре основных группы монет по составу. Первую группу составили монеты №№1, 14, 15, 16 с относительно высоким висмутом, мышьяком и никелем. Вторую группу составили монеты 
№№2, 3, 4, 5, 7, 9 с большим свинцом и золотом и самыми низкими содержаниями сурьмы. Третья группа отличается присутствием значимых концентраций цинка, что является свидетельством того, что монеты №№ 8, 10, $13,17,22$ чеканены из сплава «первой» очистки, поскольку имеющий низкую температуру плавления цинк при каждой последующей переплавке «уходит».

Для четвертой группы низкопробных монет №№ 18, 19, 21, 23, 24 характерны высокие концентрации железа, мышьяка и никеля.

Как можно заметить, группы, образованные в результате распределения по содержанию серебра в сплаве, коррелируют с группами, сформированными в результате статистической обработки показателей концентраций примесных компонентов. В случае статистической обработки вторая группа распределения по серебру разделилась и составила первую и третью группы распределения по примесям. Монеты первой группы по серебру сформировали вторую группу по примесям. Исключением является монета № 1 Подражание джучидскому дангу (877=778), которая вошла в первую группу по примесям. В четвертую «примесную» группу вошли все низкопробные монеты. Для монеты №6 можно сделать предположение, что ее состав является смесью сплавов второй и третьей групп. Монета № 12 Шадибек (Болгар) принципиально имеет те же соотношения элементов, что и первая группа, с той лишь разницей, что их содержание намного меньше. Возможно, это может быть свидетельством более качественной очистки рудного серебра. Монета №20 Гиайс-ад-Дина имеет смешанный состав третьей и четвертой групп.

\section{Выводы}

Результаты ESA и XRF (на изломе) показали хорошую сопоставимость и позволили выявить тенденции в изменении химического состава в зависимости от времени и правителя. Исследования показали, что самую высокую пробу имеют монеты, чеканенные в 747-767гг.х. - монеты №9 Джанибека (Сарай ал-Джадид), №4 Кульпы (Гулистан) и №7Азиз-Шейха (Гулистан). Монеты каждого правителя практически имеют идентичные составы и входят в одни и те же группы по содержанию серебра. Основная тенденция ухудшения качества серебряного сплава с течением времени в исследуемый период, отмеченная авторами (Шайхутдинова и др., 2018, с. 104-110.), наглядно подтверждает- ся результатами приведенных исследований. Снижение концентрации серебра до 13,5\% и практически «обесценивание» серебряных денег произошло во времена правления Гиайс-ад-Дина в 1420-х годах.

Сравнение результатов по содержанию основных компонентов монетных сплавов выявило различие в концентрации серебра и меди, определенных на поверхности и изломе XRF- методом. Наибольшее различие состава металла по результатам анализа поверхности и излома отмечается для монет № 24 - Мингли-Гарай (Крымское ханство) с трехногой тамгой и №20 - Гийасэтдин с содержанием серебра 79,751\%/46,344\% и 61,253\%/30,099\% соответственно. Эмиссионный спектральный анализ позволил определить микропримеси, содержание которых не превышает $0,001-0,0001 \%$. Статистический анализ распределения примесей показал, что для изготовления монет чеканщики использовали в разное время серебро из различных источников, причем группы монет, сформированные согласно концентрации серебра, коррелируют с группами по примесному составу. В работе выявлены монеты, чеканенные из исходной очищенной руды, о чем свидетельствуют высокие концентрации цинка. Согласно сравнительному анализу микроэлементного состава, часть монет имеет «смешанный» состав сплавов, что свидетельствует о переплавке и смешении серебра и меди отличающегося происхождения.

Результаты археометрических исследований позволяют сделать некоторые выводы и гипотезы историко-нумизматического аспекта. В середине XIV в. единое государство Золотая Орда фактически распадается на две части: левобережье Волги, где друг друга сменяли золотоордынские ханы и правобережье, где от имени Абдаллаха, позднее Мухаммада, единолично правил всесильный Мамай. На левобережной части Золотой Орды монеты чеканили Сарай, Сарай ал-Джадид и др. города, где вес монет снижался до 1,365. Азак и Крым чеканили монеты весом 1,10, но доля серебра в монете не уменьшалось. Монеты №№ 1,5 , чеканенные от имени Мухаммада и Абдаллаха, показывают, что в Мамаевой Орде серебро в сплаве снижалось, хотя общий вес монеты оставался прежним. Это предположение требует дальнейших исследований с анализом большего коли-чества монет.

Снижение веса серебра наблюдается и в подражаниях XIV в., чеканенных в Сарае 
ал-Джадиде и Гулистане. Происхождение этих подражательных монет не совсем ясно. Возможно, они чеканились не на том монетном дворе, где чеканились подлинные монеты (хотя указывалось тот же самый монетный двор). В таком случае становится ясным уменьшении концентрации серебра в составе монет. Такое снижение более $90 \%$ в начале XV в. становится нормой, и в составе монет ханов Шадибека, Пулада вплоть до Дервиша, чекана Болгар, т.е. 805 - 822 г.х. Реформа Шадибека проводилась запрещением монет старого образца. Монеты XIV в. не участвовали денежном обращении XV в., и одновременное нахождение монет XIV в. и XV в. в кладах XV в. не встречается: ни в Каратунском (24.200 монет) дотохтамышских монет $15,95 \%$, ни в Мало-Атрясском (12.480 монет) кладах монет Токтамыша нет. В этот период в Булгарском улусе завершается как чеканка медных монет, так и контрамаркирование серебра и меди.

В монетах Гийасэтдина (Мухаммад) и Мухаммада с тамгой (с 822 г. х.=1419 г.) наблюдается резкое снижение серебра в сплаве монет. Это приводит к выпадению серебра в клады и постепенному сокращению товарно-денежных отношений в Булгарском улусе. На территории Болгара обнаружен всего 1 клад из трех монет XV в., хотя в ближайшей округе отдельные клады XV в. встречаются, что говорит о потере значения города Болгара как торгово-экономического центра.

Авторы выражают благодарность заведующему Музеем археологии Республики Татарстан А.С.Мухаметшиной за предоставление нумизматического материала и А.И.Бугарчеву за помощь в атрибуции монет.

\section{ЛИТЕРАТУРА}

Мухамадиев А.Г. Булгаро-татарская монетная система XII-XV вв. М.: Наука, 1983. 168 с.

Храмченкова Р.Х., Беговатов Е.А., Шайхутдинова Е.Ф., Ситдиков А.Г. Предварительные результаты археометрических исследований серебряных монет 10 века Волжской Болгарии // Поволжская археология. 2015. № 3(13) . С. 176-188.

Шайхутдинова Е.Ф. О химическом составе поверхностного слоя булгарских монет XV в. // Нумизматические чтения Государственного Исторического музея 2018 года. К 100- летию отдела нумизматики Государственного Исторического музея. Москва, 27 и 28 ноября 2018 года. . / Отв. ред. Е.В. Захаров. М.: ГИМ, 2018. С. 104-110.

Шайхутдинова Е.Ф., Храмченкова Р.Х., Ситдиков А.Г. Компьютерная томография как метод изучения нумизматического материала: плюсы и минусы // НЗО № 6. 2016. С. 113-119.

Ioanid E.G., Ioanid A., Rusu D.E., Doroftei F. Surface investigation of some medieval silver coins cleaned in high- frequency cold plasma // Journal of Cultural Heritage. 2018. 12 (2), pp. 220-226.

Kantarelou V., Ager F. J., Eugenidou D., Chaves F., Andreou A., Kontou E., Katsikosta N., Respaldiza M.A., Serafin P., Sokaras D., Zarkadas C., Polikreti K., Karydas A.G. X-ray Fluorescence analytical criteria to assess the fineness of ancient silver coins: Application on Ptolemaic coinage // Spectrochimica Acta Part B: Atomic Spectroscopy. 2011. 66(9-10), P. 681-690.

Khramchenkova R. , Safina I., Drobyshev S., Batasheva S., Nuzhdin E., Fakhrullin R. Scanning Electron Microscopy for Investigation of Medieval Coins and Frescos from the Republic of Tatarstan // Nanotechnologies and Nanomaterials for Diagnostic, Conservation and Restoration of Cultural Heritage. Advanced Nanomaterials. / Ed. Giuseppe Lazzara and Rawil Fakhrullin. Amsterdam, Kidlington, Camdridge: ELSEVIER, 2018, P. 1-23.

Khramchenkova R.Kh., Degryze P., Sitdikov A.G., Kaplan P.Yu. Dynamics of Chemical Composition Variation of 18th - 19th Century Russian Glass // GlassCeram. 2017. No 74. P.180-184.

Pitarch A., Queralt I., Alvarez- Perez A. Analysis of Catalonian silver coins from the Spanish War of Independence period (1808-1814) by Energy Dispersive X-ray Fluorescence // Nuclear Instruments and Methods in Physics: Beam Interactions with Materials and Atoms. 2011, (269 (3)), P. 308-312.

Rezida Khramchenkova, Eugenia Shaykhutdinova, Aleksey Bugarchev, Bulat Gareev, Airat Sitdikov. Interdisciplinary study of 13 th century silver coins of the Juchid (based on the materials of the Burundukovsky hoard, Tatarstan, Russia // ActaImeko. 2017. Vol 6. No 3. P. 87-93.

Sitdikov A., Khramchenkova R., Shaykhutdinova E. Technological Characteristics In Manufacturing Of Cast Coins // European Research Studies Journal. 2017. T. 20. № S. C. 170-176.

Voropai E.S., Ermalitskaya K.F., Sidorovich V.M., Plavinsky A.N. Analysis of silver coins by double-pulse laser-atomic emission spectroscopy // BSU, Series 1: Physics. Mathematics. Computer science 2013. №1. PP. 11-16. 


\section{Информация об авторах:}

Федан Павел Владимирович, научный сотрудник Музея археологии, Институт археологии им. A.X. Халикова AН РТ (г. Казань, Россия); Pavel.fedan@mail.ru

Мухаметшин Джамиль Габдрахимович, научный сотрудник ГБУК «Болгарский государственный историко-архитектурный музей-заповедник». (г. Болгар, Россия); djamil78@list.ru.

Храмченкова Резида Хавиловна, кандидат физико-математических наук, старший научный сотрудник, Институт археологии им. А.Х. Халикова АН РТ; Казанский Федеральный университет (г. Казань, Россия); rezidahram@mail.ru

Ситдиков Айрат Габитович, член-корреспондент АН РТ, доктор исторических наук, декан, доцент, Казанский (Приволжский) федеральный университет; начальник, Институт археологии им. А.Х. Халикова АН РТ (г. Казань, Россия); sitdikov_a@mail.ru

\section{REFERENCES}

Mukhamadiev, A. G. 1983. Bulgaro-tatarskaya monetnaya sistema XII-XVvv. (The Bulgar-Tatar monetary system of the 12th-15th cc.). Moscow: "Nauka" Publ. (in Russian).

Khramchenkova, R. Kh., Begovanov, E. A., Shaykhutdinova, E. F., Sitdikov, A. G. 2015. In Povolzhskaya arkheologiya (Volga River Region Archaeology) 13 (3)., 176-188 (in Russian).

Shaykhutdinova, E. F., 2018. In Zakharov, E. V. (ed.). Numizmaticheskie chteniya Gosudarstvennogo istoricheskogo muzeya 2018 goda (Numismatic Readings of the State Historical Museum of 2018). Moscow: State Historical Museum, 104-110 (in Russian).

Shaykhutdinova, E. F., Khramchenkova, R. Kh., Sitdikov, A. G. 2016. In Numizmatika Zolotoi Ordy (Golden Horde Numismatics) 6., 113-119 (in Russian).

Ioanid E.G., Ioanid A., Rusu D.E., Doroftei F. 2018. In Journal of Cultural Heritage. 2 (12), 220-226.

Kantarelou V., Ager F. J., Eugenidou D., Chaves F., Andreou A., Kontou E., Katsikosta N., Respaldiza M.A., Serafin P., Sokaras D., Zarkadas C., Polikreti K., Karydas A.G. 2011. In Spectrochimica Acta Part B: Atomic Spectroscopy. 66(9-10), 681-690.

Khramchenkova R., Safina I., Drobyshev S., Batasheva S., Nuzhdin E., Fakhrullin R. 2018. In Giuseppe Lazzara and Rawil Fakhrullin (eds.). Nanotechnologies and Nanomaterials for Diagnostic, Conservation and Restoration of Cultural Heritage. Advanced Nanomaterials. Amsterdam, Kidlington, Camdridge: ELSEVIER, $1-23$.

Khramchenkova R.Kh., Degryze P., Sitdikov A.G., Kaplan P.Yu. 2017. In GlassCeram. 74., 180-184.

Pitarch A., Queralt I., Alvarez- Perez A. 2011. In Nuclear Instruments and Methods in Physics: Beam Interactions with Materials and Atoms., 269 (3), 308-312.

Rezida Khramchenkova, Eugenia Shaykhutdinova, Aleksey Bugarchev, Bulat Gareev, Airat Sitdikov, 2017. In ActaImeko 3(6), 87-93.

Sitdikov, A., Khramchenkova, R., Shaykhutdinova, E.2017. In European Research Studies Journal. S (20), $11-16$.

Voropai E.S., Ermalitskaya K.F., Sidorovich V.M., Plavinsky A.N. 2013. In Vestnik Beloruskogo gosudarstvennogo universiteta. Fizika, matematika, informatika (Bulletin of the Belarusian State University: Physics. Mathematics. Computer science) (1), 11-16. (in Russian)

\section{About the Authors:}

Fedan Pavel V., Institute of Archaeology named after A. Kh. Khalikov, Tatarstan Academy of Sciences. Butlerov Str., 30, Kazan, 420012, the Republic of Tatarstan, Russian Federation; Pavel.fedan@mail.ru

Mukhametshin Dzhamil G. Candidate of Historical Sciences. Bolgar State Historical and Architectural Museum-Reserve. Nazarovyh St., 67, Bolgar, 422840, the Republic of Tatarstan, Russian Federation; djamil78@list.ru.

Khramchenkova Rezida Kh. Candidate of Phisics-Mathematics Sciences. Institute of Archaeology named after A.Kh. Khalikov, Tatarstan Academy of Sciences. Butlerov St., 30, Kazan, 420012, the Republic of Tatarstan, Russian Federation; Kazan (Volga Region) Federal University. Kremlyovskaya St., 18, Kazan, 420000, the Republic of Tatarstan, Russian Federation; ; RezidaHram@mail.ru

Sitdikov Airat G. TAS Corresponding Member. Doctor of Historical Sciences. Head of department, Kazan (Volga Region) Federal University. Kremlyovskaya St., 18, Kazan, 420000, the Republic of Tatarstan, Russian 
Federation; Institute of Archaeology named after A. Kh. Khalikov, Tatarstan Academy of Sciences. Butlerov Str., 30, Kazan, 420012, the Republic of Tatarstan, Russian Federation; sitdikov_a@mail.ru

Статья поступила в журнал 01.08.2020 г. Статья принята к публикации 01.09.2020 г.

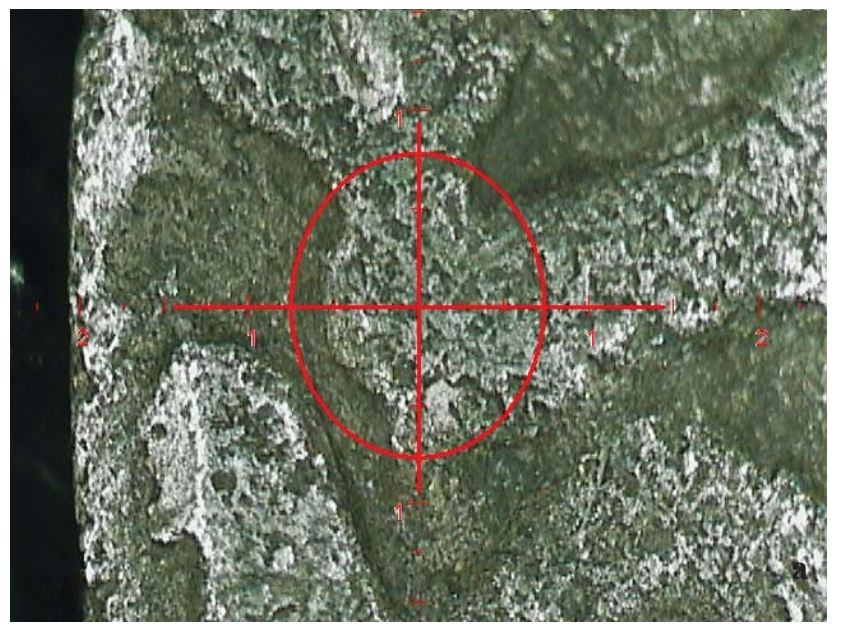
Авторы внесли равноценный вклад в работу.

Рис. 1. Снимки фокусировки при изучении методом XRF: a - поверхности, б - излома монеты.

Fig 1. Focusing images obtained during studies using the XRF method: $a$ - surface, $b$ - coin fracture.
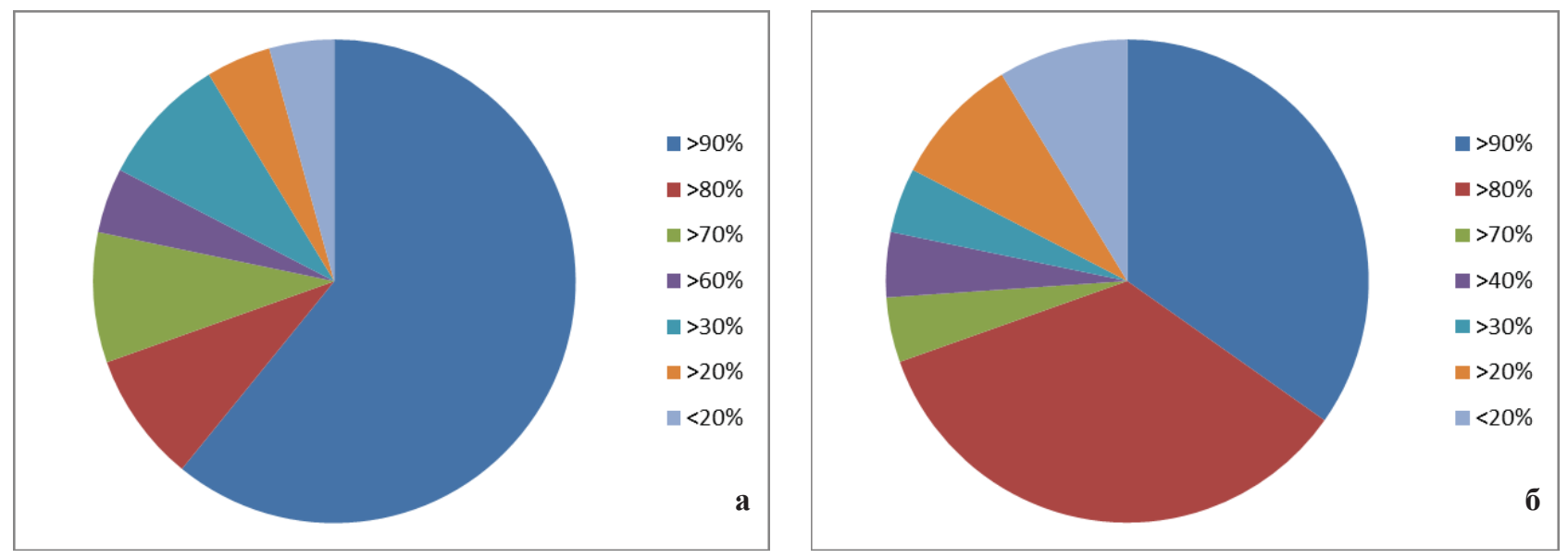

Рис. 2. Распределение монет согласно содержанию серебра: а - на поверхности, б - на изломе.

Fig 2. Coin distribution based on silver content: $a-$ on the surface, $b-$ on the fracture.
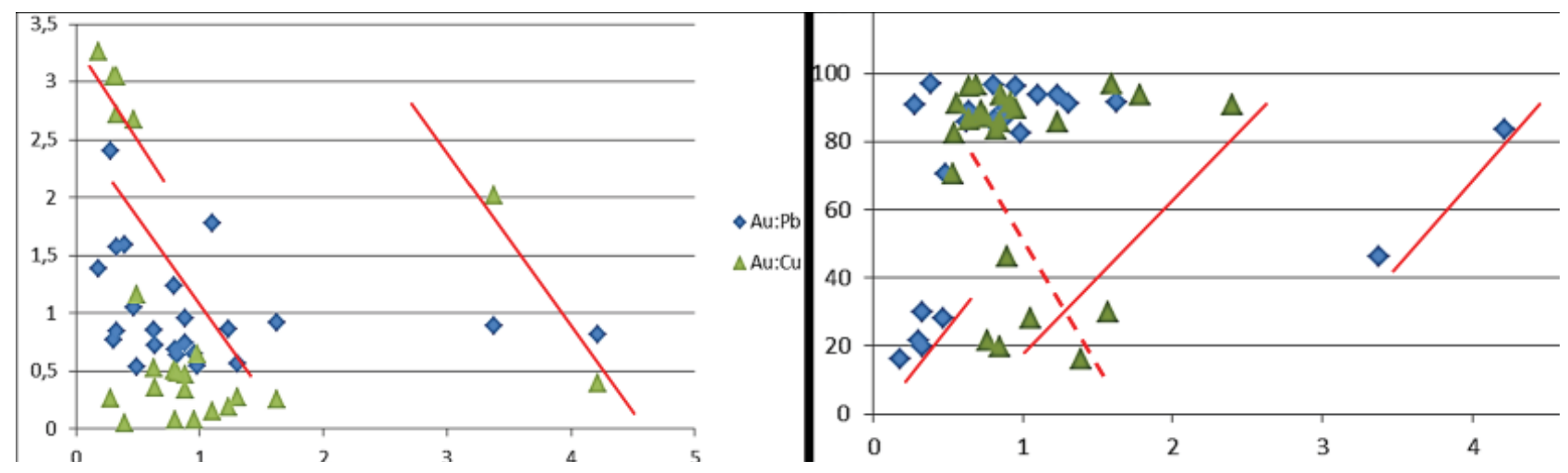

Рис. 4. Статистическая диаграмма соотношения компонентов серебряных сплавов по данным ESA.

Fig 4. Statistical diagram showing the ratio of silver alloy components based on ESA data. 


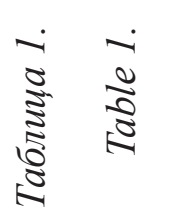

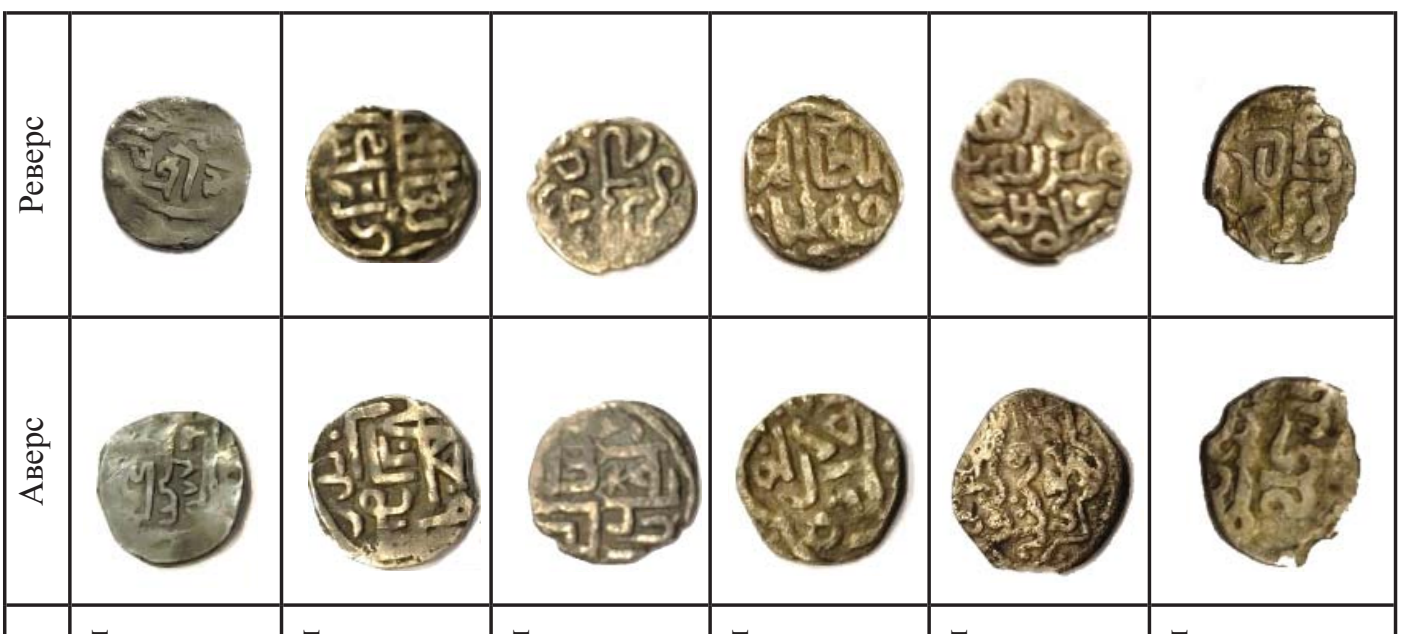

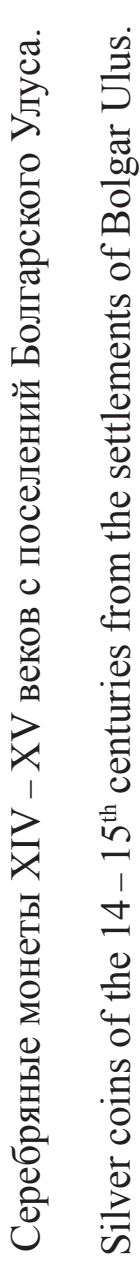

\begin{tabular}{|c|c|c|c|c|c|c|}
\hline 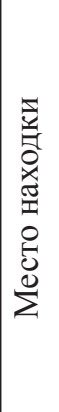 & 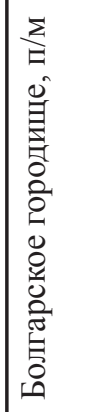 & 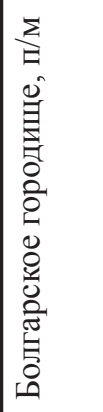 & 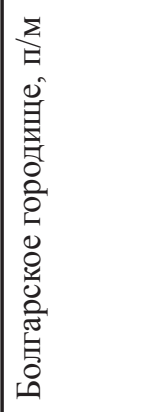 & 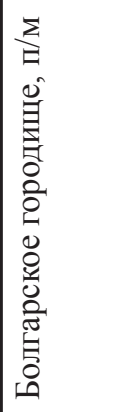 & 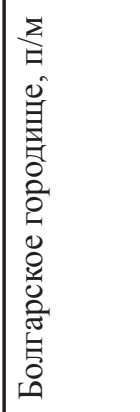 & 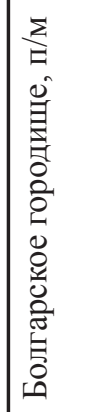 \\
\hline 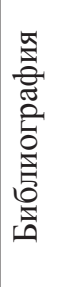 & & & & 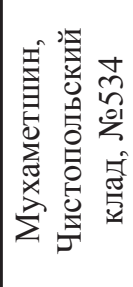 & 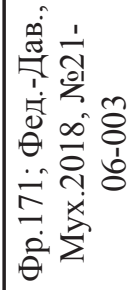 & \\
\hline 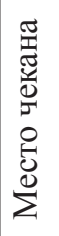 & $\begin{array}{l}\hat{\tilde{u}} \\
\text { ô. } \\
\text { ô }\end{array}$ & 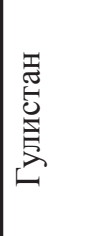 & 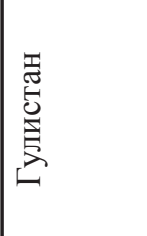 & 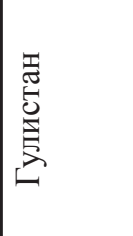 & 孚 & 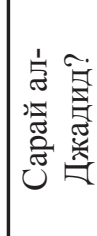 \\
\hline 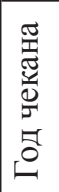 & $\begin{array}{l}\infty \\
\stackrel{\infty}{N} \\
\stackrel{N}{*} \\
\infty\end{array}$ & 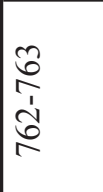 & in & 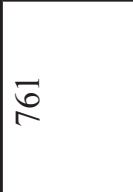 & $\stackrel{R}{i}$ & 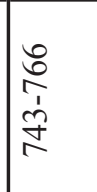 \\
\hline $\begin{array}{l}\dot{s} \\
\tilde{j} \\
\tilde{D}\end{array}$ & $\stackrel{\overbrace{}}{\sim}$ & $\exists$ & $\mid \begin{array}{l}\infty \\
\infty \\
0\end{array}$ & $\begin{array}{l}\bar{\infty} \\
0 \\
0\end{array}$ & $\hat{\sigma}_{0}$ & $\begin{array}{l}0 \\
0 \\
0\end{array}$ \\
\hline 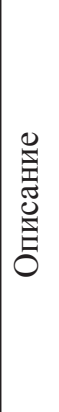 & 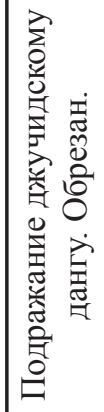 & 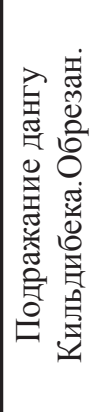 & 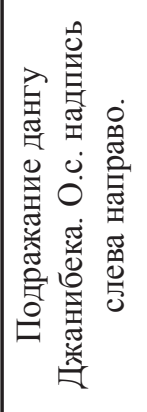 & 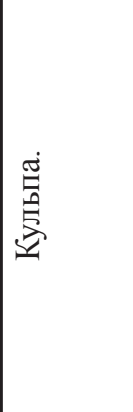 & 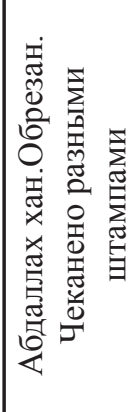 & 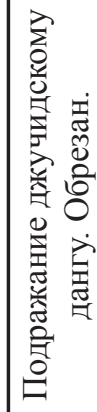 \\
\hline 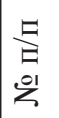 & - & $\sim$ & $m$ & $\nabla$ & in & 0 \\
\hline
\end{tabular}




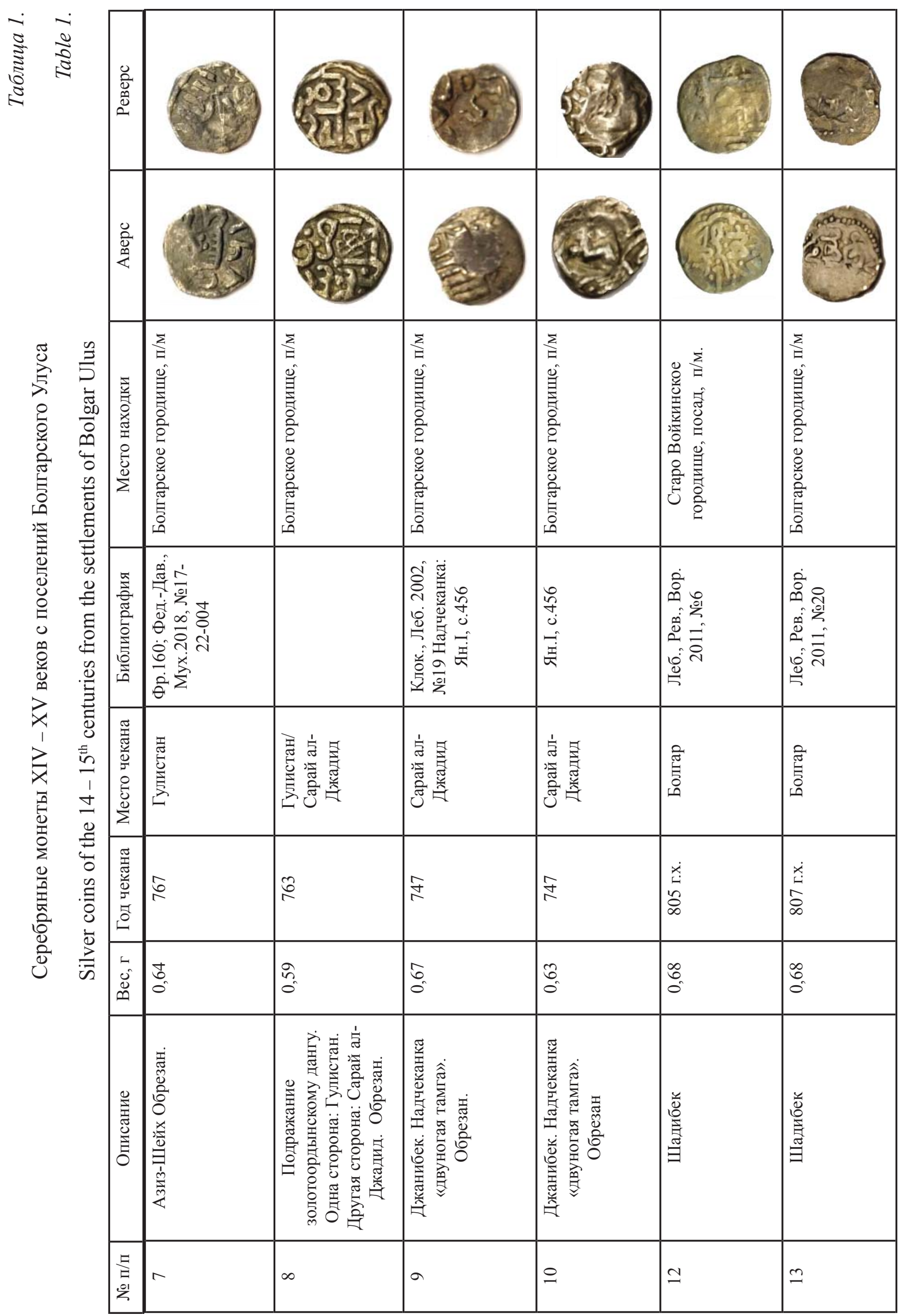




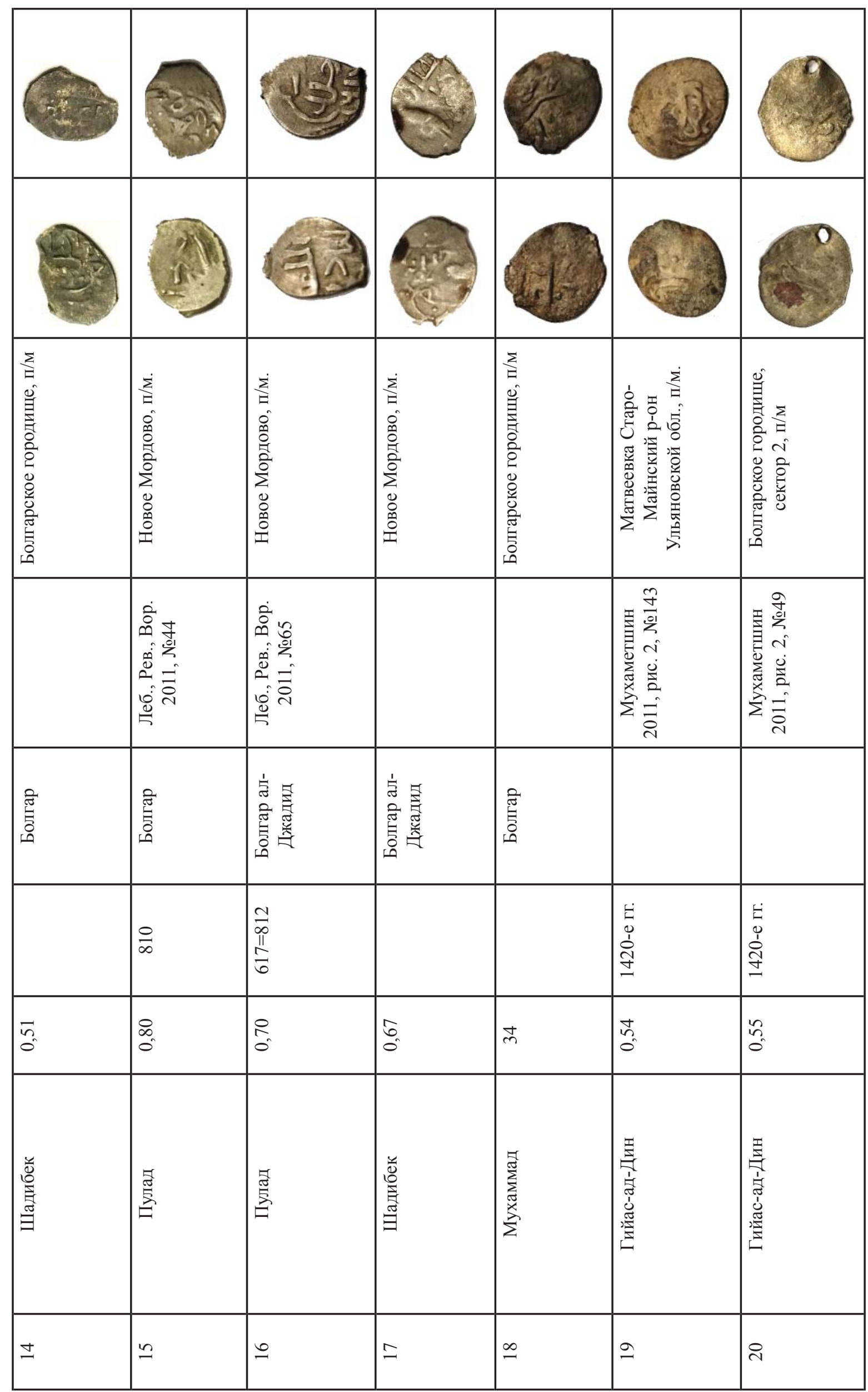




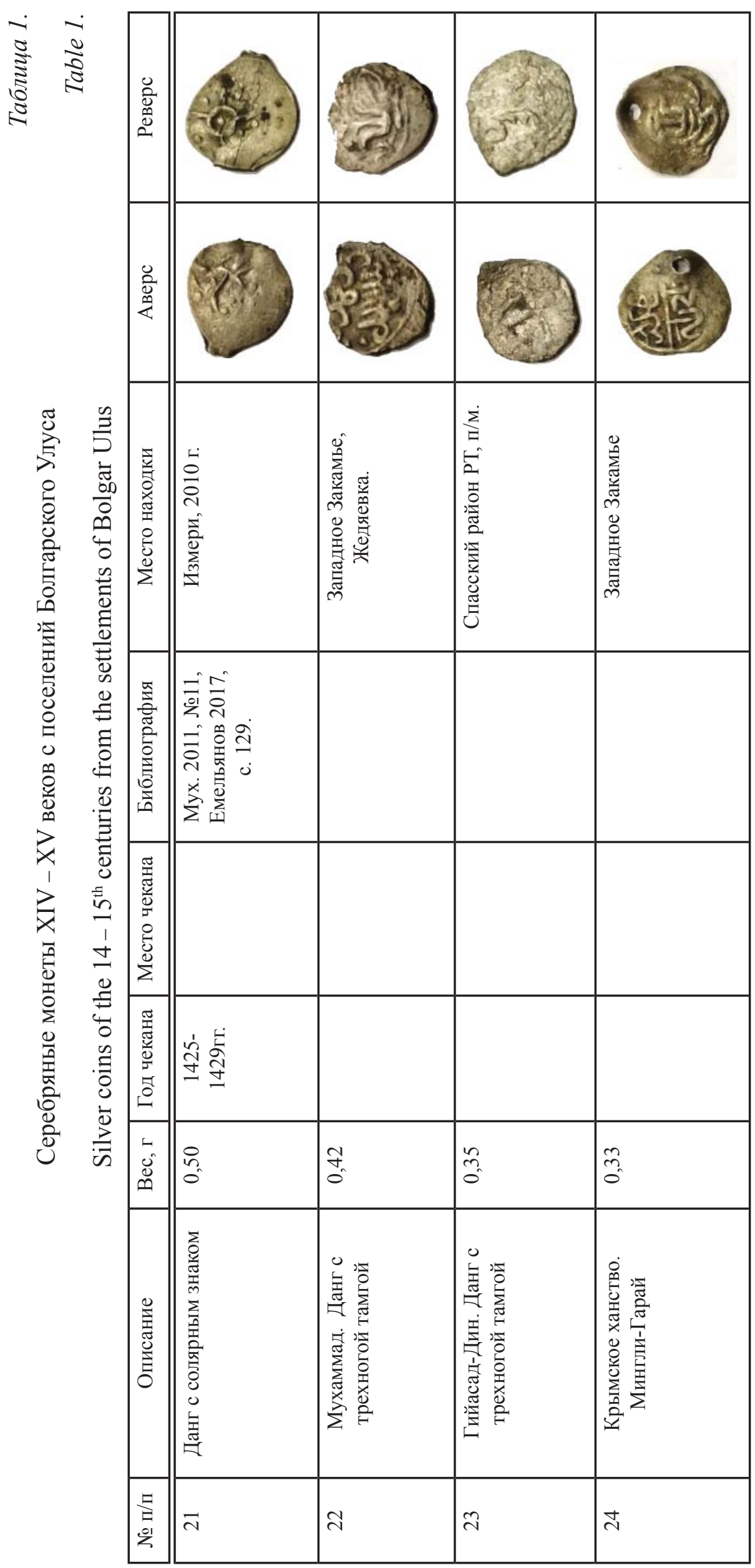


Результаты анализа химического состава серебряных монет

Таблища 2.

Results of an analysis of the chemical composition of silver coins

Table 2.

\begin{tabular}{|c|c|c|c|c|c|c|c|c|c|c|c|c|c|c|c|c|c|}
\hline Монета & № обр & метод & уч-к & Ag & $\mathrm{Cu}$ & Au & $\mathbf{B i}$ & $\mathbf{P b}$ & Sb & Sn & Zn & $\mathrm{Fe}$ & As & Co & $\mathbf{N i}$ & Mn & $\mathbf{P}$ \\
\hline \multirow{3}{*}{ Кульпа. Болгар } & \multirow{3}{*}{4} & XRF & пов. & 95,76 & 0,39 & 0,45 & & 1,73 & & & & 1,67 & & & & & \\
\hline & & XRF & изл. & 96,93 & 1,31 & 0,30 & & 1,29 & & & & 0,18 & & & & & \\
\hline & & ESA & & 95,69 & 2,17 & 0,34 & 0,024 & 1,67 & 0,0027 & 0,0029 & & & 0,0016 & 0,0011 & 0,0016 & 0,0092 & 0,049 \\
\hline \multirow{3}{*}{$\begin{array}{c}\text { Подр. дангу } \\
\text { Джанибека }\end{array}$} & \multirow{3}{*}{9} & XRF & пов. & 97,66 & 0,49 & 0,62 & & 0,48 & & & & 0,75 & & & & & \\
\hline & & XRF & изл. & 96,74 & 1,81 & 0,61 & & 0,56 & & & & 0,29 & & & & & \\
\hline & & ESA & & 97,71 & 0,97 & 0,32 & 0,042 & 0,90 & 0,0019 & 0,0016 & 0,0041 & & 0,0032 & 0,0009 & 0,00013 & 0,0004 & 0,025 \\
\hline \multirow{3}{*}{$\begin{array}{c}\text { Подр. дангу. } \\
\text { Джанибека }\end{array}$} & \multirow{3}{*}{3} & XRF & пов. & 95,20 & 1,64 & 1,16 & & 1,42 & & & & 0,58 & & & & & \\
\hline & & XRF & изл. & 93,85 & 3,87 & 0,84 & & 1,44 & & & & & & & & & \\
\hline & & ESA & & 93,48 & 3,97 & 1,05 & 0,021 & 0,96 & 0,0015 & 0,0017 & 0,0022 & & 0,0047 & 0,0003 & 0,00028 & 0,036 & 0,44 \\
\hline \multirow{3}{*}{$\begin{array}{c}\text { Азиз шейх? } \\
\text { Гулистан }\end{array}$} & \multirow{3}{*}{7} & XRF & пов. & 96,73 & 0,83 & 1,34 & & 0,82 & & 0,02 & & 0,26 & & & & & \\
\hline & & XRF & изл. & 96,40 & 1,89 & 0,72 & & 0,52 & 0,24 & 0,064 & & 0,16 & & & & & \\
\hline & & ESA & & 95,53 & 1,50 & 1,25 & 0,038 & 1,59 & 0,0025 & 0,0007 & & & 0,0027 & 0,0018 & 0,0022 & 0,0016 & 0,056 \\
\hline \multirow{3}{*}{$\begin{array}{c}\text { Подр. дангу. } \\
\text { Гулистан? }\end{array}$} & \multirow{3}{*}{1} & XRF & пов. & 94,20 & 1,07 & 0,93 & & 0,20 & & 0,02 & & 3,58 & & & & & \\
\hline & & XRF & изл. & 91,66 & 6,21 & 1,23 & 0,053 & 0,75 & & & & 0,1 & & & & & \\
\hline & & ESA & & 92,02 & 5,88 & 0,87 & 0,092 & 0,88 & 0,029 & 0,022 & 0,0075 & & 0,15 & 0,0003 & 0,0016 & 0,005 & 0,019 \\
\hline \multirow{3}{*}{$\begin{array}{c}\text { Подр. дангу. } \\
\text { Кильдибека }\end{array}$} & & XRF & пов. & 94,53 & 3,32 & 0,23 & 0,04 & 1,35 & & & & 0,53 & & & & & \\
\hline & 2 & XRF & изл. & 90,92 & 6,61 & 0,21 & 0,073 & 1,95 & & & & 0,23 & & & & & \\
\hline & & ESA & & 93,57 & 4,97 & 0,08 & 0,098 & 1,20 & 0,0012 & 0,0018 & 0,0012 & & 0,0018 & 0,0001 & & 0,0007 & 0,046 \\
\hline & & XRF & пов. & 96,25 & 1,85 & 1,11 & & 0,52 & & 0,02 & 0,00 & 0,25 & & & & & \\
\hline 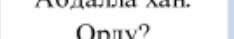 & 5 & XRF & изл. & 93,58 & 4,64 & 0,94 & & 0,70 & 0,12 & 0,031 & & & & & & & \\
\hline & & ESA & & 91,48 & 5,79 & 1,16 & 0,06 & 1,38 & 0,0053 & 0,037 & & & 0,0035 & 0,001 & 0,00066 & 0,0035 & 0,031 \\
\hline & & XRF & пов. & 96,65 & 1,57 & 0,96 & 0,03 & 0,27 & & 0,10 & & 0,42 & & & & & \\
\hline Пулад. Болгар ал- & 17 & XRF & изл. & 91,15 & 6,84 & 0,99 & 0,047 & 0,45 & & 0,097 & & 0,42 & & & & & \\
\hline & & ESA & & 85,23 & 11,85 & 0,95 & 0,13 & 1,21 & 0,15 & 0,38 & 0,045 & & 0,031 & 0,0016 & 0,00058 & 0,011 & 0 \\
\hline & & XRF & пов. & 95,51 & 2,68 & 0,80 & & 0,55 & & 0,11 & 0,22 & 0,13 & & & & & \\
\hline 1 & 8 & XRF & изл. & 89,62 & 8,29 & 0,67 & & 0,78 & & 0,13 & 0,51 & & & & & & \\
\hline & & ESA & & 86,85 & 9,67 & 0,68 & 0,095 & 1,39 & 0,48 & 0,25 & 0,47 & & 0,019 & 0,0015 & 0,0037 & 0,021 & 0,052 \\
\hline & & XRF & пов. & 77,30 & 21,82 & 0,62 & & 0,22 & & 0,03 & & & & & & & \\
\hline Шадибек. Болгар & 14 & XRF & изл. & 87,11 & 11,54 & 0,67 & 0,039 & 0,61 & & 0,039 & & & & & & & \\
\hline & & ESA & & 88,46 & 8,65 & 0,61 & 0,210 & 1,64 & 0,17 & 0,16 & 0,0056 & & 0,047 & 0,0016 & 0,003 & 0,0022 & 0,031 \\
\hline & & XRF & пов. & 97,12 & 1,75 & 0,62 & & 0,26 & & 0,06 & & 0,20 & & & & & \\
\hline Шадибек. Болгар & 12 & XRF & изл. & 85,75 & 13,09 & 0,48 & & 0,69 & & & & & & & & & \\
\hline & & ESA & & 86,83 & 12,07 & 0,25 & 0,01 & 0,64 & 0,036 & 0,069 & 0,0054 & & 0,0067 & 0,0008 & 0,00097 & 0,0004 & 0,043 \\
\hline & & XRF & пов. & 97,03 & 2,07 & 0,55 & & 0,30 & & 0,06 & & & & & & & \\
\hline Шадибек. Болгар & 13 & XRF & изл. & 88,93 & 8,91 & 0,48 & & 0,59 & 0,82 & 0,24 & & & & & & & \\
\hline & & ESA & & 85,23 & 11,73 & 0,54 & 0,06 & 1,43 & 0,43 & 0,31 & 0,17 & & 0,031 & 0,0014 & 0,0013 & 0,014 & 0,033 \\
\hline & & XRF & пов. & 83,43 & 15,37 & 0,63 & 0,01 & 0,26 & & 0,02 & & 0,27 & & & & & \\
\hline Пулад. Болгар & 15 & XRF & изл. & 82,58 & 16,07 & 0,74 & 0,046 & 0,44 & & & & 0,12 & & & & & \\
\hline & & ESA & & 71,27 & 26,58 & 0,62 & 0,13 & 1,09 & 0,14 & 0,076 & 0,0054 & & 0,054 & 0,0011 & 0,0038 & 0,0055 & 0 \\
\hline & & XRF & пов. & 95,25 & 3,79 & 0,58 & 0,04 & 0,26 & & 0,07 & & & & & & & \\
\hline 少- & 16 & XRF & изл. & 86,56 & 12,00 & 0,62 & 0,06 & 0,52 & 0,15 & 0,092 & & & & & & & \\
\hline & & ESA & & 81,69 & 15,57 & 0,58 & 0,23 & 1,70 & 0,051 & 0,03 & 0,0028 & & 0,11 & 0,0007 & 0,0016 & 0,0044 & 0 \\
\hline Мухаммад ибн & & XRF & пов. & 91,87 & 4,53 & 2,63 & & 0,47 & & 0,27 & 0,03 & 0,20 & & & & & \\
\hline Тимур. С & 22 & XRF & изл. & 83,76 & 9,71 & 3,19 & & 0,66 & & 0,31 & 0,12 & 2,24 & & & & & \\
\hline трехногой тамгой. & & ESA & & 84,62 & 6,82 & 3,02 & 0,045 & 1,17 & 0,07 & 1,71 & 0,14 & 2,26 & 0,026 & 0,0002 & 0,0006 & 0,021 & 0,023 \\
\hline & & XRF & пов. & 93,05 & 5,84 & 0,56 & & 0,39 & & 0,16 & & & & & & & \\
\hline Дек. Сараи & 10 & XRF & изл. & 85,84 & 12,45 & 0,60 & & 1,00 & & 0,11 & & & & & & & \\
\hline & & ESA & & 63,88 & 31,62 & 0,58 & 0,027 & 1,61 & 0,82 & 1,28 & 0,045 & & 0,035 & 0,0015 & 0,0054 & 0,001 & 0,019 \\
\hline & & XRF & пов. & 86,26 & 12,89 & 0,37 & & 0,40 & & 0,08 & & & & & & & \\
\hline Подр. дангу Белед & 6 & XRF & изл. & 70,52 & 28,68 & 0,37 & & 0,43 & & & & & & & & & \\
\hline & & ESA & & 83,19 & 15,74 & 0,25 & 0,024 & 0,28 & 0,43 & 0,039 & 0,0043 & & 0,0013 & 0,0011 & 0,00019 & 0,0013 & 0,019 \\
\hline & & XRF & пов. & 79,75 & 16,08 & 2,91 & 0,08 & 0,56 & 0,18 & 0,43 & & & & & & & \\
\hline Крй गи Т араи. & 24 & XRF & изл. & 46,34 & 49,92 & 2,56 & 0,089 & 0,73 & 0,1 & 0,27 & & & & & & & \\
\hline & & ESA & & 40,77 & 55,12 & 0,83 & 0,084 & 0,81 & 0,87 & 0,54 & 0,016 & 0,03 & 0,85 & 0,0056 & 0,016 & 0,024 & 0,022 \\
\hline & & XRF & пов. & 61,25 & 34,10 & 0,59 & 0,06 & 1,82 & 0,17 & 0,51 & & 1,49 & & & & & \\
\hline inc & 20 & XRF & изл. & 30,09 & 67,17 & 0,25 & 0,024 & 1,28 & 0,23 & 0,41 & & 0,55 & & & & & \\
\hline $\mathrm{IH}$ & & ESA & 1 & 49,26 & 49,45 & 0,13 & 0,1 & 0,58 & 0,041 & 0,21 & 0,033 & 0,01 & 0,088 & 0,003 & 0,0052 & 0,012 & 0,08 \\
\hline & & ESA & 2 & 31,77 & 67,02 & 0,32 & 0,003 & 0,02 & 0,15 & 0,25 & 0,0029 & 0,09 & 0,24 & 0,0045 & 0,0032 & 0,027 & 0,089 \\
\hline
\end{tabular}


Результаты анализа химического состава серебряных монет

Таблища 2.

Results of an analysis of the chemical composition of silver coins

Table 2.

\begin{tabular}{|c|c|c|c|c|c|c|c|c|c|c|c|c|c|c|c|c|c|}
\hline \multirow{3}{*}{$\begin{array}{c}\text { Тамга "солярный } \\
\text { знак" }\end{array}$} & \multirow{3}{*}{21} & XRF & пов. & 35,11 & 58,95 & 0,35 & & 0,98 & 0,12 & 0,25 & & 4,24 & & & & & \\
\hline & & XRF & изл. & 28,27 & 66,20 & 0,35 & & 0,85 & 0,033 & 0,25 & & 4,05 & & & & & \\
\hline & & ESA & & 28,75 & 67,39 & 0,36 & 0,03 & 0,57 & 0,12 & 0,74 & 0,041 & 1,39 & 0,5 & 0,0024 & 0,013 & 0,024 & 0,029 \\
\hline \multirow{3}{*}{ Мухаммад. Болгар } & \multirow{3}{*}{18} & XRF & пов. & 31,69 & 65,79 & 0,37 & & 0,94 & 0,12 & 0,18 & & 0,91 & & & & & \\
\hline & & XRF & изл. & 21,57 & 75,23 & 0,23 & & 0,62 & 0,093 & 0,2 & & 2,05 & & & & & \\
\hline & & ESA & & 27,39 & 70,18 & 0,28 & 0,021 & 0,75 & 0,15 & 0,28 & 0,031 & 0,6 & 0,19 & 0,0024 & 0,0047 & 0,024 & 0,044 \\
\hline \multirow{3}{*}{\begin{tabular}{|c} 
Гийас-ад-Дин. \\
Данг с трехногой \\
тамгой
\end{tabular}} & \multirow{3}{*}{23} & XRF & пов. & 26,61 & 67,23 & 0,39 & & 1,13 & 0,12 & 0,30 & 0,13 & 4,08 & & & & & \\
\hline & & XRF & изл. & 19,94 & 75,29 & 0,25 & & 0,69 & 0,19 & 0,25 & 0,12 & 3,28 & & & & & \\
\hline & & ESA & & 21,89 & 73,55 & 0,35 & 0,02 & 0,62 & 0,13 & 0,89 & 0,13 & 1,79 & 0,54 & 0,0034 & 0,029 & 0,024 & 0,019 \\
\hline \multirow{3}{*}{ Гийас-ад-Дин } & \multirow{3}{*}{19} & XRF & пов. & 13,49 & 83,22 & 0,11 & & 0,85 & 0,13 & 0,34 & & 1,86 & & & & & \\
\hline & & XRF & изл. & 16,19 & 80,62 & 0,14 & & 1,13 & 0,12 & 0,41 & & 1,4 & & & & & \\
\hline & & ESA & & 13,44 & 83,61 & 0,21 & 0,021 & 0,55 & 0,37 & 0,9 & 0,013 & 0,47 & 0,27 & 0,0029 & 0,0084 & 0,021 & 0,086 \\
\hline
\end{tabular}

